\title{
Insidious progression of paraparesis secondary to type III spinal meningeal cyst: a study of six difficult cases
}

\author{
$\mathrm{T} \mathrm{Yayama}^{1}, \mathrm{~S} \mathrm{Kobayashi}^{1}, \mathrm{~K} \mathrm{Uchida}^{1}, \mathrm{Y} \mathrm{Kokubo}^{1}, \mathrm{H}$ Nakajima $^{1}, \mathrm{R} \mathrm{Sato}^{1}$, A Bangirana $^{2}, \mathrm{~T} \mathrm{Takamura}^{1}$ \\ and $\mathrm{H} \mathrm{Baba}^{1}$ \\ ${ }^{1}$ Faculty of Medical Sciences, Department of Orthopaedics and Rehabilitation Medicine, Fukui University, Fukui, Japan \\ and ${ }^{2}$ Department of Orthopaedic Surgery, Makerere University School of Medicine, Kampala, The Republic of Uganda
}

\begin{abstract}
Study design: Case report
Setting: Neuro-orthopaedic Unit, Fukui University Hospital, Japan.

Case report: We studied six patients with insidious progression of paraparesis caused by thoracic and thoracolumbar spine type III spinal meningeal cyst and intradural arachnoid cyst, who underwent microsurgical decompression. Histologically, some samples showed oedematous and hypertrophic changes of the arachnoidal tissue together with occasional tophaceous deposits and calcification. Surgical treatment was complete excision of the cyst, or wide fenestration of these membrane, and close a communicating fistula, if detectable. All patients improved neurologically after microscopic surgery.

Conclusion: We stress the significance of neuroimaging and neurological assessment in patients with gradual progression of paraparesis caused by intradural arachnoid cyst, but surgical procedure and timing of operative intervention require further considerations.
\end{abstract}

Spinal Cord (2008) 46, 159-161; doi:10.1038/sj.sc.3102079; published online 22 May 2007

Keywords: spinal meningeal cyst; arachnoid cyst; thoracolumbar spine; myelopathy; cauda equina syndrome; microscopic surgery

\section{Introduction}

Intradural arachnoid cyst, a type III lesion according to the classification proposed by Nabors et al., ${ }^{1}$ causes insidious paraparesis or chronic cauda equina syndrome. It may also present with clinical features of intermittent relapse or a comparatively lengthy remission. Neurological symptoms vary widely, based on the magnitude of mechanical compression, differences in anatomical location and extent, and possible alterations in the size as well as amount of intracyst fluid retention. ${ }^{2}$

This report reviews the case files of six patients with extensive arachnoid cysts who presented with unusual progressive paraparesis.

\section{Case series}

Between 1991 and 2005, we treated 28 patients for intraspinal meningeal cyst associated with neurological symptoms. Of these, 18 patients were diagnosed with type II meningeal cysts ('Tarlov perineural cyst' ${ }^{3}$ ) and three

Correspondence: Dr T Yayama, Faculty of Medical Sciences, Department of Orthopaedics and Rehabilitation Medicine, Fukui University, Matsuokashimoaizuki 23, Eiheiji, Fukui 910-1193, Japan.

E-mail: yayama@u-fukui.ac.jp

Received 14 November 2006; revised 25 February 2007; accepted 7 April 2007; published online 22 May 2007 had type IB sacral meningocele lesions. One patient had an intraspinal bronchogenic cyst at $\mathrm{C} 1$ level and this case was published previously. ${ }^{4}$ All of the other six patients with type III lesions underwent surgery. The aim of surgery was gross resection of the cysts together with closure of the communicating fistula, if detectable.

\section{Presentation of case 5}

A 61-year-old woman was referred to our University Medical Centre for progressive cauda equina syndrome. She noticed numbness of both feet in September 2000. The numbness occasionally worsened, but also disappeared at other times. In August 2002, she had difficulty in micturition and was referred to our hospital.

On admission, she had hypesthesia below the bilateral L5 area. Muscle weakness was not significant and deep tendon reflexes were normal. On urological examination, dysuria was found. Magnetic resonance imaging demonstrated an extended intradural cystic lesion at the level from L1 down to L4, pushing the cauda equina to the lateral sides, and a large extradural cystic lesion was noted between the L5 and S4 levels (Figure 1).

During surgery, the laminae between L1 and L5 were removed en bloc, using a threaded wire saw. A midline 


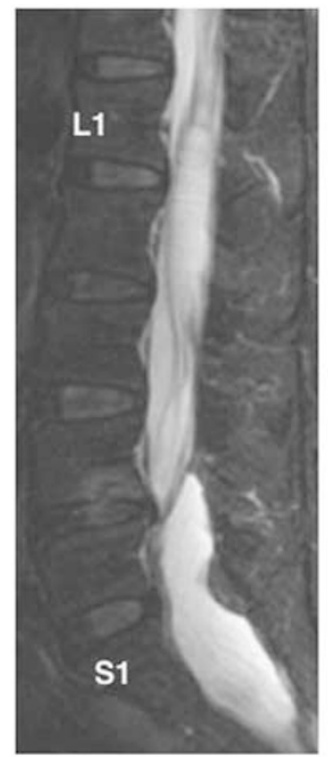

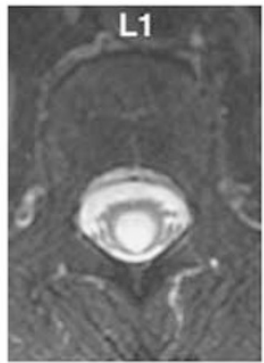

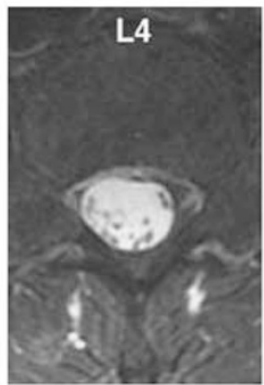

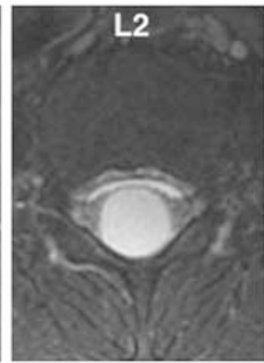
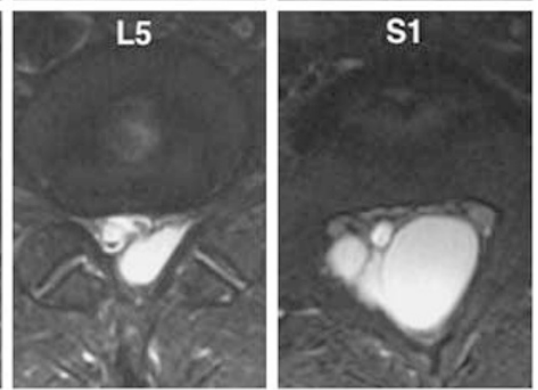

Figure 1 Magnetic resonance imaging (1.5 T Signa, GE, T2-weighted image) showing an extensive intradural arachnoidal cyst and extradural cyst of Case 5. Transaxial images at various vertebral levels show different sizes of the cyst at different levels.
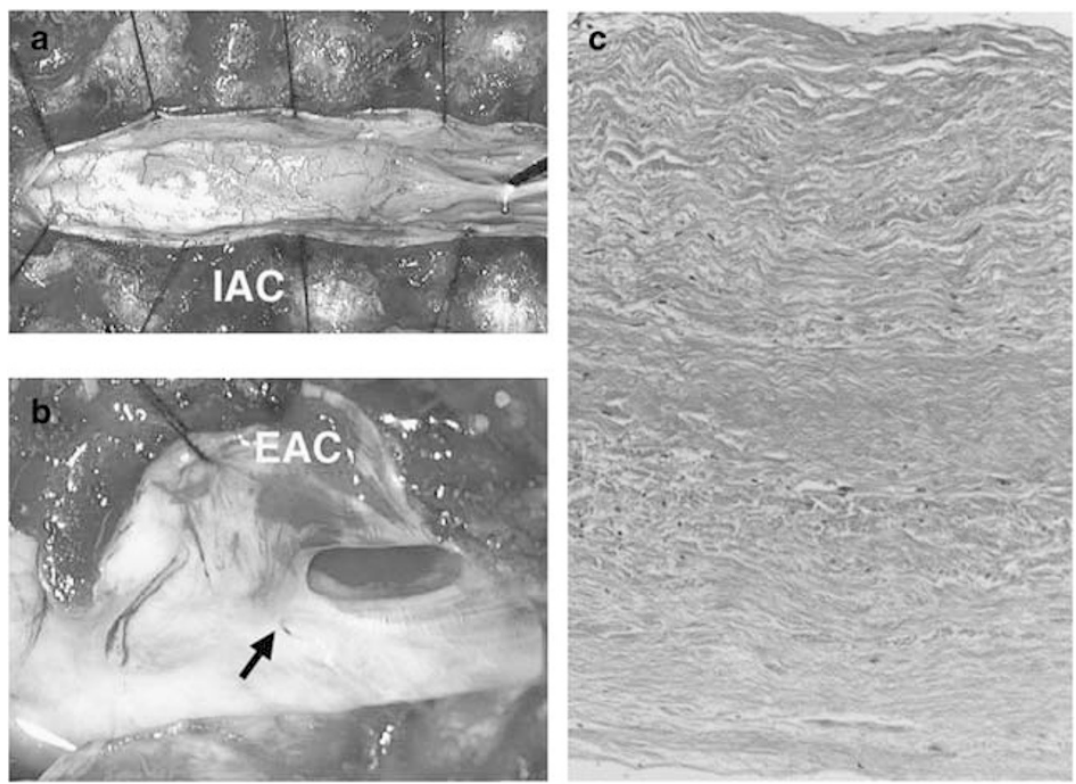

Figure 2 Intraoperative photographs of Case 5 showing intradural arachnoid cyst (IAC, a) and extradural arachnoid cyst (EAC, b) A small communicating fistula is evident (arrow). Photomicrograph of the resected arachnoid cyst is seen in (c) (haematoxylin and eosin staining, $\times 10$ objective).

durotomy was performed at the L2-L4 level and the intradural arachnoidal cyst was exposed (Figure 2a). Then, the extradural cyst was carefully retracted and the interior of the lesion was exposed. A small communicating orifice of a fistula was identified at the intervertebral level of L4-L5 (Figure 2b). Injection of physiological saline resulted in fluid leakage from the arachnoidal cyst to the extradural cyst. Microsurgically, the arachnoid cyst was resected and the communicating orifice securely closed.

Histological examination of the cyst wall revealed hypertrophy of the arachnoid membrane (Figure 2c). The postoperative course was uneventful. The patient was ambulatory 1 week after surgery. Leg paralysis improved but urinary dysfunction persisted.

\section{Discussion}

The exact mechanism of intradural arachnoid cyst formation is still unclear and multiple causative factors have been proposed: congenital origin, idiopathic, previous traumatic injury, inflammation, surgery and subarachnoid haemorrhage. In our series, two patients had had a previous episode 
Table 1 Patients demographic data

\begin{tabular}{|c|c|c|c|c|c|c|c|c|c|}
\hline Case no. & $\begin{array}{l}\text { Age, } \\
\text { gender }\end{array}$ & Past history & $\begin{array}{c}\text { Frankel-ASIA } \\
\text { (preop } \rightarrow \text { postop) }\end{array}$ & $\begin{array}{l}\text { Level } \\
\text { of cyst }\end{array}$ & $\begin{array}{l}\text { Fistula } \\
\text { orifice }\end{array}$ & Surgical procedure & $\begin{array}{l}\text { Range of cyst } \\
\text { resection }\end{array}$ & $\begin{array}{l}\text { Surgery-related } \\
\text { complications }\end{array}$ & $\begin{array}{l}\text { Follow-up } \\
\text { (years) }\end{array}$ \\
\hline 1 & $73, F$ & NS & $\mathrm{C} \rightarrow \mathrm{C}$ & T10-L1 & T10-T11 & Laminectomy (T9-L1) & T10-T11 & $\begin{array}{l}\text { CSF leakage } \\
\text { (transient) }\end{array}$ & 7.0 \\
\hline 2 & $49, \mathrm{M}$ & $\begin{array}{l}\text { L1 compression } \\
\text { fracture }\end{array}$ & $\mathrm{D} \rightarrow \mathrm{E}$ & L1-L2 & L1-L2 & Laminectomy (L1-L2) & L1-L2 & None & 6.7 \\
\hline 3 & $52, \mathrm{~F}$ & NS & $C \rightarrow D$ & T5-T7 & T6 & Laminectomy (T4-T8) & T5-T7 & None & 6.2 \\
\hline 4 & $71, \mathrm{~F}$ & NS & $E \rightarrow E$ & T9-L2 & T12 & Laminectomy (T8-L2) & T9-L2 & None & 5.3 \\
\hline 5 & $61, F$ & NS & $\mathrm{D} \rightarrow \mathrm{E}$ & $\begin{array}{c}\text { L1-L4 } \\
\text { (intradural) } \\
\text { L5-S4 } \\
\text { (extradural) }\end{array}$ & L4-L5 & $\begin{array}{l}\text { Re-capping laminotomy } \\
\text { (L1-L5) }\end{array}$ & L2-L4, L5-S1 & None & 4.0 \\
\hline 6 & $62, \mathrm{M}$ & Meningitis & $B \rightarrow D$ & T4-T10 & T7 & $\begin{array}{l}\text { Hemilaminectomy } \\
(\mathrm{T} 1-\mathrm{T} 10)\end{array}$ & T4-T10 & None & 1.0 \\
\hline
\end{tabular}

Abbreviations: CSF: cerebrospinal fluid, NS: not significant.

Re-capping laminotomy: resected laminae were again sutured.

of vertebral compression fracture or meningitis, leading to cyst formation. In case 5 , the patient had no antecedent history, suggesting that intradural cysts are at least initially congenital in nature, and that extradural cysts might develop from arachnoidal herniation through a congenital defect or congenital diverticulum associated with neural tube defects. 3

The diagnosis is usually established by computed tomography (CT) myelography and magnetic resonance imaging (MRI): CT myelography can demonstrate communication with the subarachnoid space, and MRI is obviously helpful for identifying widening or localized indentation of the subarachnoidal space. ${ }^{1,2}$ Static fluid collection within the lesion is well visualized by MRI, but it is possible that inflow and outflow within the lesion through a communicating orifice create a signal void on MR images, which is, however, a potential sign of the presence of a communicating fistula.

Surgical management is another issue that needs to be discussed. A simple lesion without any extension is treated by gross resection of the cyst followed by closure of the communicating fistula on the arachnoid membrane. However, dense fibrous adhesions or extending some vertebral segments may prevent complete cyst resection. Extensive fenestration of these cyst membranes performed to allow maximal communication with the subarachnoid space may result in neurological improvement. The timing of surgery obviously depends on the degree and magnitude of physical impairment, and should be weighed against possible adverse effects of surgical treatment (Table 1).

In conclusion, we stress the importance of careful assessment of neurological and neuroimaging findings in patients with temporary and intermittent resolution of neurological complications secondary to intradural arachnoid cysts. Treatment of such cysts should include removal of the cyst and closure of the communicating orifice, followed by steps to maintain stable spinal anatomy.

\section{Disclaimer}

No author has any financial ties to any commercial parties.

\section{References}

1 Nabors MW, Pait TG, Byrd EB, Karim NO, Davis DO, Kobrine AI et al. Updated assessment and current classification of spinal meningeal cysts. J Neurosurg 1988; 68: 366-377.

2 Kendall BE, Valentine AR, Keis B. Spinal arachnoidal cyst: clinical and radiological correlation with prognosis. Neuroradiology 1982; 22: 225-234.

3 Voyadzis JM, Bhargava P, Henderson FC. Tarlov cysts: a study of 10 cases with review of the literature. J Neurosurg 2001; 95 (Suppl 1): 25-32.

4 Baba H, Okumura Y, Ando M, Imura S, Morioka K, Noriki S. A high cervical intradural extramedullary bronchogenic cyst: case report. Paraplegia 1995; 33: 228-232.

5 Wilkins RH. Intraspinal cysts. In: Wilkins RH, Rengachary SS (eds). Neurosurgery, vol 3. McGraw-Hill: New York, 1996, pp 3509-3519. 